\title{
Oxidation of cyclohexanol and cyclohexene with triazenido complexes of chromium immobilized in biosorption FAU supports
}

\author{
H. Figueiredo ${ }^{\text {a }}$, B. Silva ${ }^{\text {a }}$, I. Kuźniarska-Biernacka ${ }^{\text {b }}$, A.M. Fonseca ${ }^{\text {b }}$, R. Medina ${ }^{c}$, S. Rasmussen ${ }^{c}$, \\ M.A. Bañares ${ }^{c}$, I.C. Neves ${ }^{\text {b,* }}$, T. Tavares ${ }^{\text {a,* }}$ \\ a Centro de Engenharia Biológica, Universidade do Minho, Campus de Gualtar, 4710-057 Braga, Portugal \\ ${ }^{\mathrm{b}}$ Departamento de Química, Centro de Química, Universidade do Minho, Campus de Gualtar, 4170-057 Braga, Portugal \\ ${ }^{\mathrm{c}}$ Instituto de Catálisis y Petroleoquímica, CSIC, E-28049 Madrid, Spain
}

\section{H I G H L I G H T S}

- Fau supported $\mathrm{Cr}$ catalysts were prepared by biosorption of waste metal.

- Diphenyltriazene derivatives proved to be suitable coordination agents for CrFAU.

- CrFAU catalysts were successfully used in mild condition oxidation reactions.

- Cr leaching was effectively reduced by the immobilization procedure.

\section{A R T I C L E I N F O}

\section{Article history}

Received 4 December 2013

Received in revised form 25 January 2014

Accepted 25 February 2014

Available online 10 March 2014

\section{Keywords:}

FAU zeolite

Chromium

1,3-Diphenyltriazenido ligands

Heterogeneous catalyst

Oxidation reactions

\begin{abstract}
A B S T R A C T
This work presents the recovery of biosorption supports as an alternative source of benign production of heterogeneous catalysts for oxidation reactions in mild conditions. $\mathrm{Cr}$-containing FAU zeolite, in sodium form ( $\mathrm{NaY}$ ) and in proton form (HY), was recovered from biosorption studies and reused as support for the preparation of heterogeneous catalysts by the flexible ligand method, using 1,3-diphenyltriazene derivatives. Results showed that the ligand play an important role in the coordination of $\mathrm{Cr}$ inside the zeolite. The catalysts showed good activity for the oxidation of cyclohexanol, reaching a maximum of 63.5\% conversion. $\mathrm{Cr}$ leaching was evaluated and it was found that the $\mathrm{Cr}$-FAU supports lost some of the $\mathrm{Cr}$ into the reaction medium, whereas immobilization of $\mathrm{Cr}$-complexes reduced the referred leaching. For the cyclohexene oxidation, a maximum $72.9 \%$ conversion was achieved with a HY zeolite-based catalyst.
\end{abstract}

(c) 2014 Elsevier B.V. All rights reserved.

\section{Introduction}

Research on environmental protection receives considerable attention from public, academia and industry. Several technologies for pollution abatement and/or remediation have been proposed and successfully implemented. One particular critical aspect of industrial contamination of the environment is heavy metal pollution. Metals tend to accumulate in organisms, therefore posing a health risk through persistence in food chains [1]. Various technologies for the treatment/prevention of heavy metal contamination in liquid systems have been developed such as ion exchange, adsorption, precipitation, filtration and dialysis/osmosis processes [2]. More recently, environmental awareness has resulted in efforts

\footnotetext{
* Corresponding authors. Tel.: +351 253604400 (T. Tavares).

E-mail addresses: ineves@quimica.uminho.pt (I.C. Neves), ttavares@deb. uminho.pt (T. Tavares).
}

for developing "green processes", whereas the current economic constraints increase the demand for recovery-reuse technologies $[3,4]$.

In order to address these two trends, a technology for the removal and recovery of hexavalent chromium has been proposed, combining the biosorption properties of the Arthrobacter viscosus bacterium with a supporting zeolite [5-10]. The bacterium performs the reduction of $\mathrm{Cr}(\mathrm{VI})$ to $\mathrm{Cr}(\mathrm{III})$, while the latter is ion-exchanged by the supporting zeolite, which is intrinsically unable to perform direct ion-exchange of chromate and dichromate anions, the most common aqueous $\mathrm{Cr}(\mathrm{VI})$ species. After the biosorption process, the resulting biosorbent-zeolite system was calcined and the resulting $\mathrm{Cr}$-zeolite is suitable for application in catalysis.

The use of $\mathrm{Cr}-\mathrm{NaY}$ zeolite recovered from biosorption studies in gas-phase catalysis has been conducted, namely, for the oxidation of 1,2-dichlorobenzene and ethyl acetate [5,11]. However, the 
utilization of $\mathrm{Cr}-\mathrm{NaY}$ matrices in liquid-phase oxidation reactions requires previous immobilization of the $\mathrm{Cr}$ species in the support, in order to overcome the possible $\mathrm{Cr}$ leaching [12-14]. Since leaching of active metal centres into the solution is undesirable, various strategies for immobilization of catalytically active metal centres in inorganic matrices have been proposed. Some of the methods to obtain the heterogeneous catalysts include coordination of the metal with ligands by anchoring it to the support or by in situ synthesis of the complex inside the host, the so called ship in bottle synthesis [15-18].

Encapsulation of metal species in zeolites is a method that has been studied for a quite long time [19] and is known to be efficient for the immobilization of transition metal complexes. Faujasite (FAU) zeolites possess well-defined supercages interlinked with three-dimensional channels with wide pore openings (12 oxygen atoms), which makes these supports ideal hosts for the encapsulation of metal complexes via the flexible ligand method. This heterogeneous class of catalysts has found application on several fields in catalysis such as preparation of fine chemicals [15], photocatalysis and electrocatalysis [17].

Oxidation of alcohols to the corresponding ketones and aldehydes is a key reaction in organic synthesis [20-22], since the selective formation of carbonyl functional groups in hydrocarbons makes them useful intermediaries for pharmaceuticals and cosmetic products [23]. Cr-containing catalysts have found application on the oxidation of several organic substrates, including cyclohexene and cyclohexanol [24-26]. The latest is of particular interest, as the liquid-phase oxidation of secondary alcohols often employs homogeneous $\mathrm{Cr}(\mathrm{VI})$ catalysts, which requires previous preparation of catalyst and demands for an efficient disposal of the metal after reaction, given its toxicity [22].

This work reports the preparation of heterogeneous chromium catalysts from Cr-biosorption FAU supports and the application of these catalysts to liquid-phase oxidation reactions in mild conditions. For the effect, 1,3-diphenyltriazene derivatives were used as ligands for the immobilization of the $\mathrm{Cr}$ species inside the framework of FAU zeolite. The oxidation of cyclohexanol and cyclohexene were chosen as model reactions for the validation of the catalytic activity.

\section{Experimental section}

\subsection{Materials and procedures}

A. viscosus was obtained from the Spanish Type Culture Collection of University of Valência. Potassium dichromate aqueous solutions were prepared by diluting $\mathrm{K}_{2} \mathrm{Cr}_{2} \mathrm{O}_{7}$ (Panreac) in distilled water, in concentrations up to $100.0 \mathrm{mg}_{\mathrm{Cr}} / \mathrm{L}$. The FAU supports, $\mathrm{NaY}$ and HY zeolites, were supplied by Zeolyst International (commercial names CBV100 and CBV400, respectively) in powder form. Bulk Si/Al ratios are 2.83 and 2.80 for $\mathrm{NaY}$ and $\mathrm{HY}$, respectively. Both zeolites were calcined at $500^{\circ} \mathrm{C}$ during $8 \mathrm{~h}$ under a dry air stream prior to use. All glassware used for experimental purposes was washed in $10 \%$ nitric acid to remove any possible interference by other metals. Atomic absorption spectrometric standards were prepared from $1000 \mathrm{mg} \mathrm{L}^{-1}$ solution. 1,3-diphenyltriazene derivatives ( $1 \mathrm{a}, 1 \mathrm{~b}$ and $1 \mathrm{c}$ ) were prepared using a previously described procedure in literature $[27,28]$. All the other chemicals and solvents used for the catalysts preparation and for the catalytic reactions were reagent grade and purchased from Aldrich.

\subsection{Immobilization of $\mathrm{Cr}$ complexes in FAU supports}

Immobilization of $\mathrm{Cr}$ (III) complexes in the Cr-FAU supports was based in a previously established procedure [29]. Cr-FAU supports were prepared by different biosorption treatments: the sample $\mathrm{CrNaY}$ was recovered from a single-batch process, whereas $\mathrm{CrNaY}_{\mathrm{SBR}}$ and $\mathrm{CrHY}_{\mathrm{SBR}}$ were obtained from processes involving sequential batch reactors (hence the suffix SBR) and in all cases an initial $100 \mathrm{mg}_{\mathrm{Cr}} / \mathrm{L}$ dichromate solution was used [6]. All recovered samples were previously calcined at $500{ }^{\circ} \mathrm{C}$ under dry air flow for $8 \mathrm{~h}$. For the immobilization of 1,3-diphenyltriazenido chromium complex in the Cr-FAU supports the coordination was obtained with ligand 1,3-diphenyltriazene (1a). Two more ligands, 1,3-bis( $p$-methylphenyl)triazene (1b) and 1,3-bis( $p$-nitrophenyl) triazene (1c) were used for coordination with $\mathrm{Cr}$ in $\mathrm{CrNaY}$ support in order to compare the efficiency of $\mathrm{Cr}$ immobilization.

The catalysts were prepared via a flexible ligand method consisting of three steps: in situ complex synthesis, liquid-solid extraction and stabilization. For the first step, $0.28 \mathrm{mmol}$ of the selected ligand in $100 \mathrm{~mL}$ of ethanol solution and $1.0 \mathrm{~g}$ of $\mathrm{Cr}-\mathrm{FAU}$ host (previously dried at $150{ }^{\circ} \mathrm{C}$ under vacuum) were refluxed for $24 \mathrm{~h}$ with moderate stirring. The solid is recovered by filtration and dried overnight at $60^{\circ} \mathrm{C}$. Liquid-solid Soxhlet extraction was conducted with $50 \mathrm{~mL}$ of dichloromethane for $5 \mathrm{~h}$. Finally, the stabilization of the catalyst was performed under moderated stirring at room temperature for $24 \mathrm{~h}$ with $50 \mathrm{~mL}$ of $0.01 \mathrm{M} \mathrm{NaNO}_{3}$ solution. The solid is recovered from this solution by filtration, followed by overnight drying at $60^{\circ} \mathrm{C}$.

\subsection{Catalytic oxidation of cyclohexene and cyclohexanol}

The oxidation reaction of cyclohexene is conducted in a $50 \mathrm{~mL}$ three-way flask equipped with a condenser and thermometer. The reaction mixture is as follows: $5.8 \mathrm{~mL}$ decane (solvent), $0.2 \mathrm{~mL}$ cyclohexene (substrate), $0.4 \mathrm{~mL}$ toluene (internal standard for GC analysis) and $2.0 \mathrm{~mL}$ of tert-butyl hydroperoxide (TBHP) 5.5-6.0 M in decane (oxygen source). For the catalyzed reactions, an amount of $50.0 \mathrm{mg}$ of previously dried catalyst is transferred into the reaction mixture before the addition of TBHP. The reactor is placed in an oil bath at the desired reaction temperature (controlled by a thermostat at $50{ }^{\circ} \mathrm{C}$ ) and the mixture is moderately stirred for $23 \mathrm{~h}$. The evolution of cyclohexene and oxidation products is followed by GC analysis.

The oxidation reaction of cyclohexanol is conducted in similar conditions as for the oxidation of cyclohexene, with the exception of the composition of the reaction mixture which is as follows: $5.0 \mathrm{~mL}$ diethylketone (solvent), $0.3 \mathrm{~mL}$ cyclohexanol $(2.9 \mathrm{mmol}$ of substrate), $0.4 \mathrm{~mL}$ chlorobenzene (standard for GC analysis) and $2.0 \mathrm{~mL}$ of 5.5-6.0 M TBHP in decane. The reaction temperature is set to $60^{\circ} \mathrm{C}$ and the mixture is moderately stirred for $23 \mathrm{~h}$. All blank experiments, without catalyst and using NaY and HY zeolites as catalyst, were performed under the same conditions.

\subsection{Characterization procedures}

Scanning electron microscopy (SEM) surface analysis was performed on a Nova NanoSEM 200 microscope under high vacuum, coupled to EDAX - Pegasus X4M energy-dispersive spectrometer (EDS), with beam energy of $15.00 \mathrm{kV}$. X-ray photoelectronic spectra (XPS) of the supports/catalysts were obtained with a VG Escalab $200 \mathrm{R}$ XPS spectrometer fitted with an $\mathrm{Mg} \mathrm{K} \alpha$ X-ray source at $120 \mathrm{~W}$. Carbon was used as internal standard for all samples, with correction of the corresponding binding energy of $\mathrm{C}$ to $284.6 \mathrm{eV}$. Fourier-Transform Infrared spectra (FTIR) of solid samples were recorded within the $4000-500 \mathrm{~cm}^{-1}$ range with a Bomem MB104 spectrometer, using $\mathrm{KBr}$ pellets (sample/ $\mathrm{KBr}$ mass ratio was $1: 100$ ). Raman spectra of solid samples were recorded on a Perkin-Elmer Raman Station 400F fitted with a $785 \mathrm{~nm}$ wavelength laser with a maximum power at sample of $100 \mathrm{~mW}$. Accumulations, total accumulation time and power at sample 
parameters were adjusted in order to minimize the effect of background fluorescence on each sample. EPR spectra were collected with a Bruker EMX EPR spectrometer at $77 \mathrm{~K}$ using a finger dewar inserted into a Bruker standard ER4102ST cavity. The microwave frequency was around $9.42 \mathrm{GHz}$. Before acquisition of EPR spectra, the samples were dried overnight at $120^{\circ} \mathrm{C}$. Chemical analysis of $\mathrm{C}$, $\mathrm{N}$ and $\mathrm{H}$ was conducted on a Leco CHNS-932 analyzer. The determination of $\mathrm{Cr}$ content of each solid support was carried out by inductively coupled plasma atomic emission spectrometry (ICPAES) using a Philips ICP PU 7000 Spectrometer. Thermogravimetric analysis (TGA) was conducted on a Shimadzu TGA-50 instrument. Samples were placed in aluminium crucibles and were characterized between 25 and $580{ }^{\circ} \mathrm{C}$ under a constant heating rate of $6{ }^{\circ} \mathrm{C} / \mathrm{min}$ and $50 \mathrm{~mL} / \mathrm{min}$ of $\mathrm{N}_{2}$ flow. BET areas of the supports/catalysts were determined from $\mathrm{N}_{2}$ adsorption isotherms performed on an automatic Micromeritics ASAP-2000 apparatus. Samples were previously outgassed at $140{ }^{\circ} \mathrm{C}$ for $2 \mathrm{~h}$. Acid digestion of liquid samples from catalytic reactions were performed in a microwave $\left(0.5 \mathrm{~mL}\right.$ of sample for $10.0 \mathrm{~mL}$ of $\left.\mathrm{HNO}_{3}\right)$ and analysed for $\mathrm{Cr}$ in a Varian SpectrAA-250 atomic absorbance spectrometer. Liquid samples from catalytic reactions were analysed by gas chromatography on a SRI Instruments 8610 C gas chromatograph, fitted with a CP-Sil 8CB capillary column and FID detector.

\section{Results and discussion}

\subsection{Preparation and characterization of the heterogeneous $C r-F A U$ catalysts}

In the present study, Cr-FAU structures are used as hosts for the preparation of catalysts and their application in liquid-phase oxidation reactions is reported. The Cr-FAU zeolites were recovered from different batch assays supporting $\mathrm{Cr}(\mathrm{VI})$ biosorption studies. In short, the $A$. viscosus bacteria, supported on FAU zeolites, bioreduces $\mathrm{Cr}(\mathrm{VI})$ species to $\mathrm{Cr}(\mathrm{III})$ ions and these cations in aqueous medium are then easily ion-exchanged by the zeolitic support. All Cr-FAU zeolites were recovered from an initial $100 \mathrm{mg}_{\mathrm{Cr}} / \mathrm{L}$ dichromate solution, with uptake values of $11.7,8.3$ and $6.7 \mathrm{mg}_{\mathrm{Cr}} /$ $\mathrm{g}_{\text {zeolite }}$ for $\mathrm{CrNaY}, \mathrm{CrHY}_{\mathrm{SBR}}$ and $\mathrm{CrNaY}_{\mathrm{SBR}}$, respectively. This difference in uptake performance results in different $\mathrm{Cr}$ loadings of the supports. Full details on the biosorption-recovered supports were described elsewhere [6].

The recovered structures were calcined in order to remove the supported biomass and other organic matter, resulting in $\mathrm{Cr}-\mathrm{FAU}$ materials. These starting materials for preparation of the different catalysts were named $\mathrm{CrHY}_{\mathrm{SBR}}$ and $\mathrm{CrNaY}_{\mathrm{SBR}}$, for those recovered from the sequential batch process (SBR), whereas CrNaY was recovered from a single-batch process [6].

The in situ synthesis of $\mathrm{Cr}$ (III) complexes in FAU zeolite supercages was performed by the flexible ligand method in the liquid phase using an excess of the 1,3-diphenyltriazene derivatives, named 1a, 1b and 1c (Fig. 1). Three triazenido derivatives ligands with different donor and acceptor substituents in para-phenyl group were used: 1,3-diphenyltriazene (1a), 1,3-bis( $p$-methylphenyl)triazene (1b) and 1,3-bis(p-nitrophenyl)triazene (1c). All ligands could be chelated by the 1,3-nitrogen atoms [30].

The coordination of chromium by these ligands is strongly affected by the substituents in para-aryl position. The nitro group in para position of the aromatic ring decreases the coordination of triazenido as a result of its electrowithdrawing ability. However, methyl groups in para position increase the electronic density in the triazenido group, resulting in enhanced coordination. The environment medium for the coordination has also an important influence on the final complexes because it is necessary to ensure that

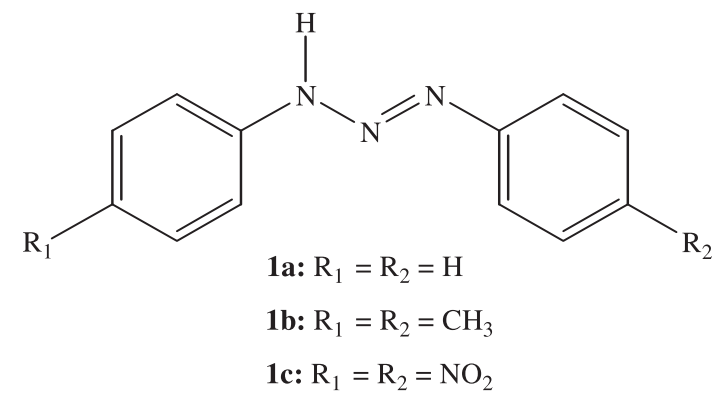

Fig. 1. Structure of 1,3-diphenyltriazene derivatives.

the deprotonation of the acidic hydrogen in triazene group occurs [31].

Several different techniques were used to evaluate the immobilization of 1,3-diphenyltriazenido chromium complexes in the supercages of the host zeolites obtained by different processes in the $\mathrm{Cr}$ catalysts.

SEM analysis is important to confirm that the calcination step after the biosorption process removes the biofilm from the zeolite [29,32]. Fig. 2 presents the field emission scanning electron micrograph (Fig. 2a) and the surface EDS spectrum (Fig. 2b) of $\mathrm{CrHY}_{\mathrm{SBR}}$ as a representative example.

The typical faujasite zeolite morphology was preserved and has well defined particles with average sizes between 0.2 and $0.5 \mu \mathrm{m}$ (Fig. 2a). No changes in the zeolite morphology or structure upon complex encapsulation were observed. Energy-dispersive X-ray analysis shows the presence of $\mathrm{Cr}$ in the matrix by the respective $\mathrm{K} \alpha$ line at $5.40 \mathrm{keV}$ [33] and a residual amount of phosphor was detected at $2.03 \mathrm{keV}$ [34], which is most likely a scattered biomass residue from calcination (Fig. 2b).

The XPS analysis provided valuable information about the presence of chromium on the surface layer of supports, as well as about the oxidation state of the metal. All catalysts revealed the presence of oxygen, sodium, silicon, nitrogen and aluminium in their XPS resolution spectra. The presence of chromium was detected in region of $\mathrm{Cr} 2 \mathrm{p}$. The spectrum showed two bands at binding energies of $577.4 \mathrm{eV}$ and $586.6 \mathrm{eV}$. The first corresponds to $\mathrm{ar} 2 \mathrm{p}_{3 / 2}$ and the second to a $\mathrm{Cr} 2 \mathrm{p}_{1 / 2}$. Fig. 3 presents the peak fitting of the signal on the $\mathrm{Cr} 2 \mathrm{p}$ XPS spectrum of $\mathrm{CrNaY}$, as an example.

After deconvolution in the $\mathrm{Cr} 2 \mathrm{p} 3 / 2$ region, the peak at $577.4 \mathrm{eV}$ is attributed to $\mathrm{Cr}(\mathrm{III})$, while signals at 581.3 and $579.5 \mathrm{eV}$ may be due to the presence of $\mathrm{Cr}(\mathrm{VI})$ [26,35]. The presence of $\mathrm{Cr}(\mathrm{III})$ is due to the reduction of $\mathrm{Cr}(\mathrm{VI})$ to $\mathrm{Cr}(\mathrm{III})$ during the biotreatment process. The biomass is responsible for this reduction, while the zeolite performed the entrapment of $\mathrm{Cr}$ (III) by ion-exchange [6,9]. Similar results were observed by Park et al. [36], who concluded that the biomass by itself would only retain $\mathrm{Cr}$ (III) ions. The presence of $\mathrm{Cr}(\mathrm{VI})$ in $\mathrm{CrNaY}$ could be due to the calcination treatment re-oxidating a fraction of the exchanged $\mathrm{Cr}(\mathrm{III})$ species to $\mathrm{Cr}(\mathrm{VI})$. This fact was reported by Weckhuysen et al., who stated that $\mathrm{Cr}(\mathrm{III})$ ion-exchanged $\mathrm{Y}$ zeolites would form chromate species upon calcination in an oxygen-rich atmosphere [37]. Since the recovered biosorption supports were calcined under dry air flow, it is likely that a partial oxidation occurred and the supports contained both $\mathrm{Cr}(\mathrm{VI})$ and $\mathrm{Cr}(\mathrm{III})$ species.

Additional structural information was obtained by Raman spectroscopy that can identify chromium species present in these catalysts. Fig. 4 presents the Raman spectra of $\mathrm{CrNaY}$ support and the homologous catalysts prepared with the three different ligands. Although the spectra are dominated by the intrinsic background fluorescence of calcined zeolitic samples [38], it is possible to identify peaks at 1360 and $942 \mathrm{~cm}^{-1}$ in $\left[\mathrm{CrL}_{1 \mathrm{a}}\right] \mathrm{NaY}$ and $\left[\mathrm{CrL}_{1 b}\right] \mathrm{NaY}$. The spectrum of $\left[\mathrm{CrL}_{1 \mathrm{c}}\right] \mathrm{NaY}$ is similar to the one 


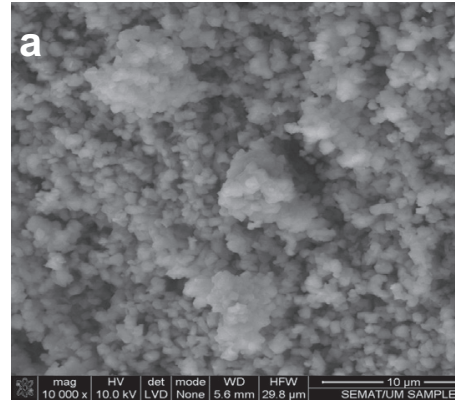

b

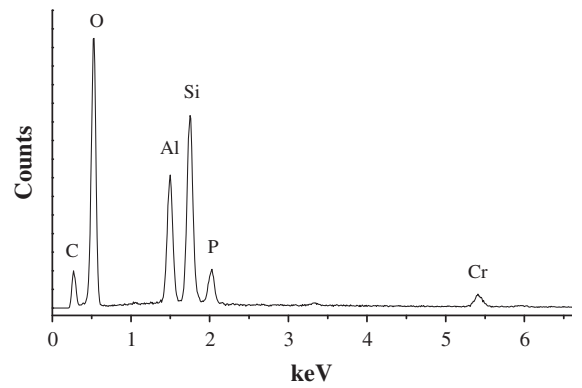

Fig. 2. (a) Scanning electron microscopy $(10.000 \times)$ and (b) energy dispersive spectrum of $\mathrm{CrHY}_{\mathrm{SBR}}$.

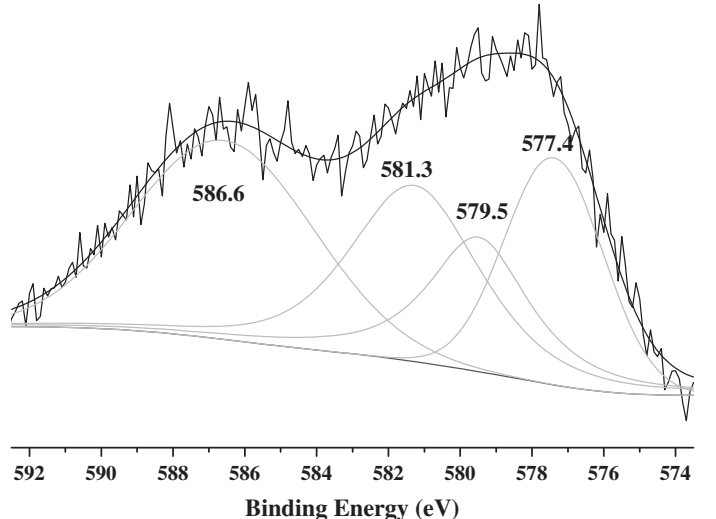

Fig. 3. Peak fitting of the $\mathrm{Cr} 2 \mathrm{p}$ region on the XPS spectrum of $\mathrm{CrNaY}$.

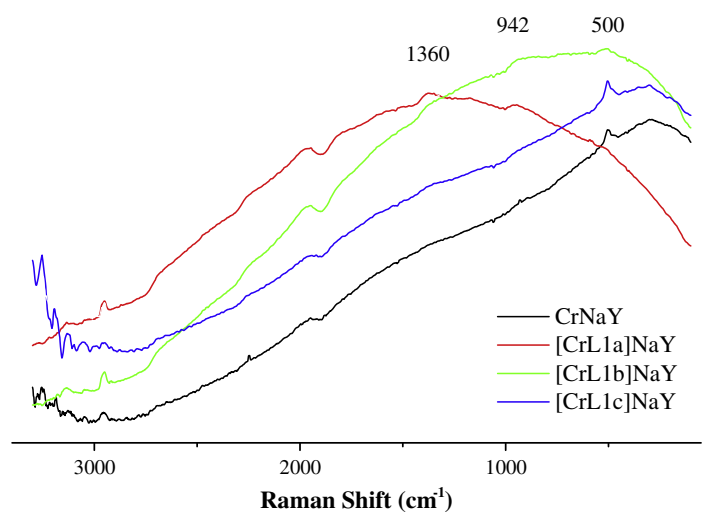

Fig. 4. Raman spectra of $\mathrm{CrNaY}$ and of the respective catalysts.

of CrNaY. The first signal corresponds to the D-band of carbon compounds [39], while the second peak resembles the most intense Raman band of alkali chromates species [26]. The presence of these species could be related to the calcination conditions that favour the oxidation of $\mathrm{Cr}(\mathrm{III})$ to $\mathrm{Cr}(\mathrm{VI})$. $\mathrm{Cr}$ (III)-related Raman bands are expected at $550 \mathrm{~cm}^{-1}$ but are not visible in the spectra, mainly due overlapping with the intense $500 \mathrm{~cm}^{-1}$ Raman band that is typical for FAU zeolites [40].

The immobilization of chromium complexes in the biosorption FAU supports was demonstrated by FTIR and EPR analysis. All FTIR spectra of biosorption FAU supports and of the catalysts are dominated by the strong bands attributed to the zeolite structure. No shift or broadening of the zeolite vibration bands is observed upon incorporation of the chromium complex. The FTIR spectra of NaY and $\mathrm{HY}$ are characterized by a very intense broad band at $c a$. $3460 \mathrm{~cm}^{-1}$, with a poor resolved shoulder at $\mathrm{ca} .3600 \mathrm{~cm}^{-1}$ attributed to the hydroxyl groups in the supercages and in the sodalite cages, respectively $[41,42]$. In the low energy region, the spectrum showed a band at $1640 \mathrm{~cm}^{-1}$ characteristic of the $\delta\left(\mathrm{H}_{2} \mathrm{O}\right)$ mode of absorbed water [43]. The band at ca. $1020 \mathrm{~cm}^{-1}$ is usually attributed to the asymmetric stretching of $\mathrm{Al}-\mathrm{O}-\mathrm{Si}$ chain of zeolite. The symmetric stretching and bending frequency bands of Al-OSi framework of zeolite appear at ca. 727 and $513 \mathrm{~cm}^{-1}$, respectively [44]. As an example, the spectra for $\mathrm{CrNaY}$ and $\left[\mathrm{CrL}_{1 \mathrm{a}}\right] \mathrm{NaY}$ provide evidence that the zeolite framework is preserved throughout calcination and immobilization of the 1,3-diphenyltriazenido chromium complex (Fig. 5). The spectrum of $\left[\mathrm{CrL}_{1 \mathrm{a}}\right] \mathrm{NaY}$ shows the bands at 1492 and $1593 \mathrm{~cm}^{-1}$, attributed to the $v(\mathrm{~N}=\mathrm{N}=\mathrm{N})$ of the triazene group, which proves that this ligand was successfully coordinated into the framework zeolite.

The EPR spectra of the triazenido chromium complexes on $\mathrm{NaY}$ and $\mathrm{CrNaY}$ are shown in Fig. 6, while Table 1 presents characteristic EPR data. The principal $g$-value of the samples was calculated from their EPR spectra by using the standard procedure $[26,45]$.

$\mathrm{CrNaY}$ exhibit a fairly sharp, slightly anisotropic signal at a $g_{\perp}$ value around 1.97 (denoted $g_{1}$ in Table 1 ), which probably represents $\mathrm{Cr}$ species in square pyramidal conformation, since the $g_{\|}$line appears to be around 1.957 [26]. The immobilized samples contain similar bands and in addition to that a signal at $g=2.0$ (denoted $g_{2}$ in Table 1). However, it should be noted that the spectral features of the $\left[\mathrm{CrL}_{1 \mathrm{c}}\right] \mathrm{NaY}$ sample are quite similar to those of the parent CrNaY. The EPR lines for FAU supports and for $\mathrm{CrL}_{1 \mathrm{a}}$ and $\mathrm{CrL}_{1 \mathrm{~b}}$ in FAU supports appear as a combination of the mentioned signals at $g=1.97$ and 2.0. Especially in the case of the $\left[\mathrm{CrL}_{1 \mathrm{a}}\right] \mathrm{HY}_{\mathrm{SBR}}$ sample an anisotropic broadening of the $g=1.97$ signal is observed, which could suggest some change in the coordination environment of $\mathrm{Cr}$

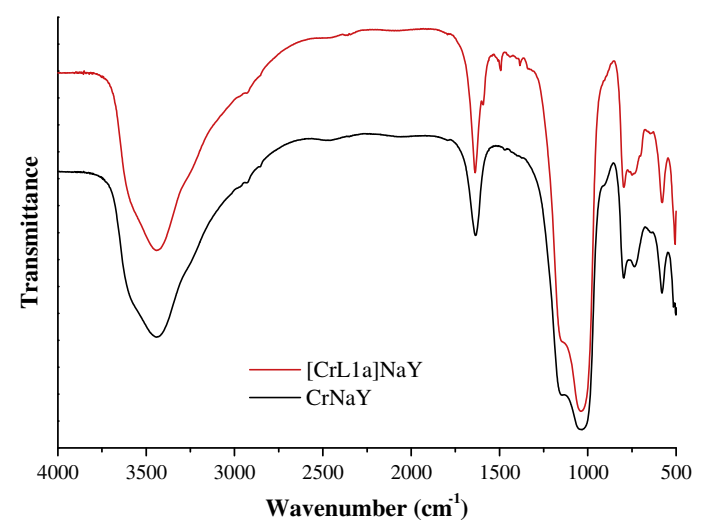

Fig. 5. Infrared spectra of $\mathrm{CrNaY}$ and $\left[\mathrm{CrL}_{1 \mathrm{a}}\right] \mathrm{NaY}$. 


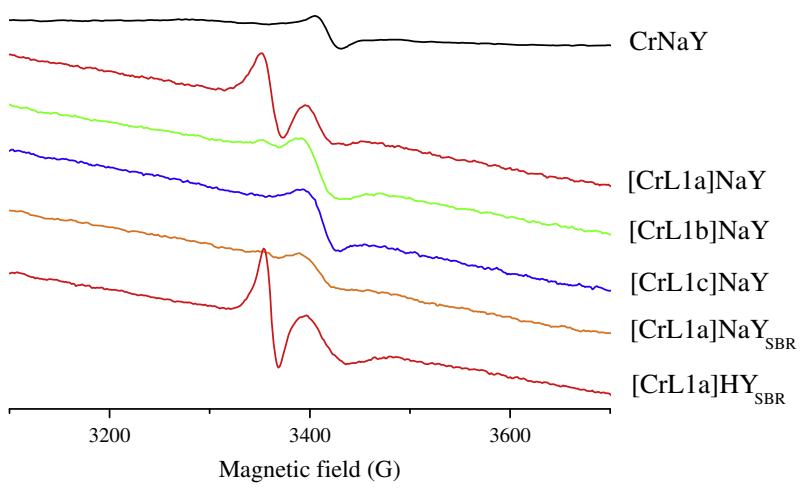

Fig. 6. EPR spectra for $\mathrm{CrNaY}$ and the respective catalysts. Data collected at $77 \mathrm{~K}$.

Table 1

EPR data for the different samples.

\begin{tabular}{|c|c|c|c|c|}
\hline \multirow[b]{2}{*}{ Sample } & \multicolumn{4}{|c|}{ EPR signals } \\
\hline & $g_{1}$ & $\begin{array}{l}\text { Band width } \\
\left(\mathrm{pp}^{\mathrm{a}}\right)(\mathrm{G})\end{array}$ & $g_{2}$ & $\begin{array}{l}\text { Band width } \\
\text { (pp) (G) }\end{array}$ \\
\hline $\mathrm{CrNaY}$ & 1.971 & 25 & & \\
\hline$\left[\mathrm{CrL}_{1 \mathrm{a}}\right] \mathrm{NaY}$ & 1.973 & 28 & 2.002 & 22 \\
\hline$\left[\mathrm{CrL}_{1 \mathrm{~b}}\right] \mathrm{NaY}$ & 1.978 & 35 & 2.003 & 20 \\
\hline$\left[\mathrm{CrL}_{1 \mathrm{c}}\right] \mathrm{NaY}$ & 1.972 & 32 & & \\
\hline$\left[\mathrm{CrL}_{1 \mathrm{a}}\right] \mathrm{NaY} \mathrm{Y}_{\mathrm{SBR}}$ & 1.976 & 32 & 2.001 & 19 \\
\hline$\left[\mathrm{CrL}_{1 \mathrm{a}}\right] \mathrm{HY}_{\mathrm{SBR}}$ & 1.975 & 39 & 2.002 & 15 \\
\hline
\end{tabular}

a $\mathrm{pp}$ : Peak to peak band width on derivative EPR spectra.

due to the complexation into FAU supercages [26]. Since the samples were only dried at $120^{\circ} \mathrm{C}$, it is reasonable to assume that some intra-zeolitic water might still be present, which coordinates to $\mathrm{Cr}(\mathrm{III})$ in the in situ synthesis of the complex.

Combined chemical, thermogravimetric and textural analyses were performed to compare the immobilization of chromium complexes within the different biosorption supports. The combined data are detailed in Table 2.

The immobilization of the $\mathrm{Cr}$ complexes in biosorption supports was confirmed by the analytical data of carbon, nitrogen and metal. The highest $\mathrm{Cr} / \mathrm{N}$ ratio observed for $\mathrm{CrNaY}_{\mathrm{SBR}}$ suggests the presence of a fraction of chromium not coordinated with the ligand. It was found that a part of this chromium could be located in framework sites that are inaccessible for the ligands [27,45]. The lower nitrogen amount in the $\left[\mathrm{CrL}_{1 \mathrm{c}}\right] \mathrm{NaY}$ catalyst shows that the complex with 1,3-bis( $p$-nitrophenyl)triazene (1c) ligand was not achieved, in agreement with Raman, FTIR and EPR analyses. These results are due to the decrease of the donor groups strength of the triazenido ligand by the $\mathrm{NO}_{2}$ group in para position in acidic medium [31].
It should be referred that the biosorption assays were performed at $\mathrm{pH} 4.00$ in order to increase the reduction of the $\mathrm{Cr}(\mathrm{VI})$ species.

The low amount of $\mathrm{Cr}$ complexes is related to the presence of the different $\mathrm{Cr}$ species in the biosorption FAU supports. $\mathrm{Cr}(\mathrm{VI})$ species detected by XPS and Raman are not coordinated with the triazenido ligands which means that only a small fraction of chromium takes part in the synthesis of the complex and this fraction is trivalent.

Thermogravimetric analysis also confirmed that immobilization of $\mathrm{Cr}$ complexes was achieved. TG and DTG curves of the biosorption FAU supports and of the catalysts show a weight loss at $110^{\circ} \mathrm{C}$ which is attributed to the loss of water molecules present in the framework of the zeolite. After the synthesis, the catalysts based in 1,3-diphenyltriazene (1a) and 1,3-bis( $p$-methylphenyl)triazene (1b) ligands presented a secondary weight loss, taking place at a higher temperature, around $410^{\circ} \mathrm{C}$, which is attributed to the decomposition of the organic matter from the complexes. Fig. 7 presents the TGA-DTG data for $\left[\mathrm{CrL}_{1 \mathrm{a}}\right] \mathrm{NaY}$, as an example.

The different weight losses observed for the catalysts confirm that the 1,3-bis( $p$-nitrophenyl)triazene (1c) ligand is not coordinated with chromium. In the case of the chromium complex formed in $\mathrm{CrNaY}_{\mathrm{SBR}}$ the TGA results show that the lower amount of the complex is related to the lower amount of entrapped chromium.

The extent of the secondary weight loss varied with the different combinations of support and 1,3-diphenyltriazene (1a) ligand. This ligand was able to form up to $2.5 \%(\mathrm{w} / \mathrm{w})$ mass of chromium complex within $\mathrm{CrNaY}$ and $\mathrm{CrHY}_{\mathrm{SBR}}$. Despite having different chromium loadings, the formation of complex with 1a ligand was comparable between these two supports.

For all catalysts, the total surface areas were calculated by the BET equation $\left(S_{\mathrm{BET}}\right)$ and the data show a reduction in area after the complexation, when compared to the respective parent supports, which is a further indication of successful immobilization $[46,47]$. The decreasing of the BET area is specially significant for the catalysts obtained from $\mathrm{CrNaY}$ and $\mathrm{CrHY}_{\mathrm{SBR}}$.

\subsection{Oxidation of cyclohexanol}

The catalytic behaviour of the different chromium complexes in biosorption FAU supports was tested for the oxidation of cyclohexanol using TBHP as an oxygen source. Blank experiments without catalyst and in the presence of parent NaY or HY were performed under identical experimental conditions. Cyclohexanone was found to be the only significant product of the reaction studied [48]. Table 3 presents the results achieved by different catalysts after $23 \mathrm{~h}$.

From the results presented in Table 3, it is seen that the presence of chromium ions on the support greatly increases cyclohexanol conversion, while parent $\mathrm{NaY}$ and $\mathrm{HY}$ zeolites proved to be

Table 2

Characterization data of the materials.

\begin{tabular}{|c|c|c|c|c|c|c|c|}
\hline \multirow[t]{2}{*}{ Support } & \multirow[t]{2}{*}{ Ligand } & \multicolumn{4}{|c|}{ Elemental analysis $(\%, \mathrm{w} / \mathrm{w})$} & \multirow{2}{*}{$\begin{array}{l}\text { TGA analysis } \\
\text { Complex mass }(\%, w / w)\end{array}$} & \multirow[t]{2}{*}{ BET surface area $\left(\mathrm{m}^{2} \mathrm{~g}^{-1}\right)$} \\
\hline & & $\mathrm{Cr}^{\mathrm{a}}$ & $C^{b}$ & $\mathrm{~N}^{\mathrm{b}}$ & $\mathrm{Cr} / \mathrm{N}$ & & \\
\hline \multirow[t]{4}{*}{$\mathrm{CrNaY}$} & & 0.75 & 0 & 0 & & & 593 \\
\hline & $1 \mathrm{a}$ & 0.71 & 0.75 & 0.19 & 3.74 & 2.5 & 196 \\
\hline & $1 \mathrm{~b}$ & 0.71 & 1.23 & 0.20 & 3.55 & 2.1 & 317 \\
\hline & $1 \mathrm{c}$ & 0.72 & 0.10 & 0.02 & & 0.2 & 563 \\
\hline \multirow[t]{2}{*}{$\mathrm{CrNaY}_{\mathrm{SBR}}$} & & 0.46 & 0 & 0 & & & 590 \\
\hline & $1 \mathrm{a}$ & 0.47 & 0.32 & 0.05 & 9.40 & 0.8 & 540 \\
\hline \multirow[t]{2}{*}{$\mathrm{CrHY}_{\mathrm{SBR}}$} & & 0.59 & 0 & 0 & & & 496 \\
\hline & $1 \mathrm{a}$ & 0.55 & 1.04 & 0.29 & 1.89 & 2.5 & 201 \\
\hline
\end{tabular}

\footnotetext{
a $\mathrm{Cr}$ loading on FAU supports determined by ICP-AES analysis.

b Carbon and nitrogen from $\mathrm{Cr}$ complexes obtained by elemental analysis.
} 


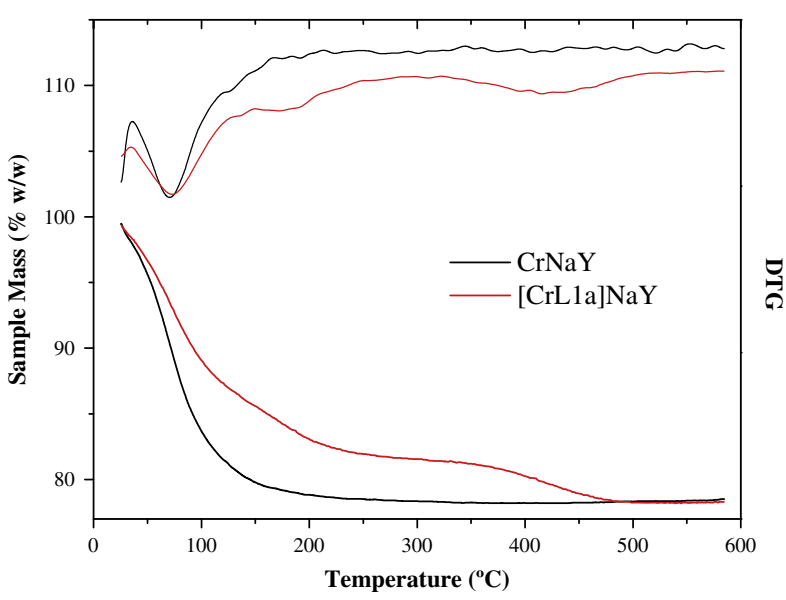

Fig. 7. TG and DTG curves of $\mathrm{CrNaY}$ and $\left[\mathrm{CrL}_{1 \mathrm{a}}\right] \mathrm{NaY}$.

Table 3

Results for the catalytic oxidation of cyclohexanol.

\begin{tabular}{lllll}
\hline Catalyst & $\begin{array}{l}\text { Cyclohexanol } \\
\text { conversion }(\%)\end{array}$ & $\begin{array}{l}\text { Analytical } \\
\text { error }(\%)\end{array}$ & TON $^{\mathrm{a}}$ & $\begin{array}{l}\text { Cr Leaching } \\
(\mu \mathrm{g})\end{array}$ \\
\hline $\begin{array}{l}\text { (blank } \\
\text { reaction) }\end{array}$ & 18.6 & \pm 3.5 & & \\
NaY zeolite & 15.8 & \pm 5.3 & & \\
HY zeolite & 14.2 & \pm 1.4 & & \\
$\mathrm{CrNaY}_{\left[\mathrm{CrL}_{1 \mathrm{a}}\right] \mathrm{NaY}}$ & 61.2 & \pm 1.2 & 246 & 47.8 \\
{$\left[\mathrm{CrL}_{1 \mathrm{~b}}\right] \mathrm{NaY}$} & 54.3 & \pm 3.0 & 243 & 28.5 \\
{$\left[\mathrm{CrL}_{1 \mathrm{c}}\right] \mathrm{NaY}$} & 63.5 & \pm 1.7 & 201 & 17.5 \\
$\mathrm{CrNaY}_{\mathrm{SBR}}$ & 56.8 & \pm 2.8 & 266 & 40.9 \\
{$\left[\mathrm{CrL}_{1 \mathrm{a}}\right] \mathrm{NaY}$} & 49.1 & \pm 4.5 & 373 & 29.6 \\
$\mathrm{CrHY}_{\mathrm{SBR}}$ & 48.0 & \pm 4.6 & 315 & 18.3 \\
{$\left[\mathrm{CrL}_{1 \mathrm{a}}\right] \mathrm{HY}$} & & \pm 1.1 & 245 & 20.1 \\
\hline
\end{tabular}

a Turnover number (TON) was determined from the converted cyclohexano moles over the initial molarity of $\mathrm{Cr}$ in the respective catalyst.

inefficient for this reaction, as the substrate conversion is very close to blank. TON values are higher for the catalysts based on NaY prepared by SBR method. This might be due to the presence of chromium species in zeolite sites that are accessible to the reactants [49].

The samples with immobilised chromium complex present a slight decrease in cyclohexanol conversion when compared to biosorption FAU supports except $\left[\mathrm{CrL}_{1 \mathrm{c}}\right] \mathrm{NaY}$. The $\mathrm{CrNaY}$ and $\left[\mathrm{CrL}_{1 \mathrm{c}}\right] \mathrm{NaY}$ catalysts led to very close cyclohexanol conversion values. This result supports the characterization data that indicated almost no complexation took place in the latter material. Since chromium leaching from $\mathrm{Cr}$-containing catalysts is acknowledged, even when TBHP oxidant is used [13], liquid samples of each reaction were digested and analysed for total chromium content. The result of this determination is presented in Table 3. It may be seen that chromium was detected on the reaction medium of all modified materials, proving that there is a contribution from homogeneous catalysis to the overall conversion. However, the immobilized catalysts prepared from biosorption FAU supports presented a smaller amount of leached chromium when compared to the correspondent untreated biosorption supports. $\mathrm{CrHY}_{\mathrm{SBR}}$ is the least leaching-prone material, while leaching from its complex immobilized counterpart, $\left[\mathrm{CrL}_{1 \mathrm{a}}\right] \mathrm{HY}_{\mathrm{SBR}}$ is negligible. Catalysts based on NaY show higher leaching of active species.

\subsection{Oxidation of cyclohexene}

The catalysts were also tested for the oxidation of cyclohexene. The reaction mechanism in the presence of $\mathrm{Cr}$-containing catalysts has already been proposed [29] and the main products obtained from this reaction are 2-cyclohexene-1-ol (CyOL), 2-cyclohexene1-one (CyONE), and 1-tert-butylperoxy-2-cyclohexene (CyOX), proving that only allylic oxidation takes place. The latter was found to behave as an intermediary towards the formation of CyONE and CyOL, which has been reported by other authors [46].

The overall conversion of cyclohexene, product selectivity and TON are presented in Table 4.

It was found that the presence of chromium in the biosorption FAU supports greatly increases the conversion of cyclohexene. The products distribution depends on catalyst used. The NaY and HY zeolites were just able to originate the intermediary CyOX. CyONE was the main product when chromium modified catalysts were used and for these catalysts a small decrease in cyclohexene conversion was observed, when compared to the parent biosorption supports.

The highest cyclohexene conversion was achieved for the $\mathrm{CrHY}_{\mathrm{SBR}}$ catalyst. The comparison of substrate conversion reached in blank reaction and in the presence of $\mathrm{NaY}$ and $\mathrm{HY}$, shows that $\mathrm{HY}$ zeolite is slightly active in this reaction, whereas $\mathrm{NaY}$ is inactive. The substrate conversion values with allowance for the background reaction (HY) are $61.1 \%$ and $59.8 \%$ for $\mathrm{CrHY}_{\mathrm{SBR}}$ and for $\left[\mathrm{CrL}_{1 \mathrm{a}}\right] \mathrm{HY}_{\mathrm{SBR}}$, respectively, and they are of the same order of magnitude as for $\mathrm{CrNaY}_{\mathrm{SBR}}$ based counterparts. This fact explains the higher conversion of $\mathrm{CrHY}$ based catalysts and they can be considered as bifunctional catalysts for this particular reaction.

$\left[\mathrm{CrL}_{1 \mathrm{c}}\right] \mathrm{NaY}$ catalyst leads to lower substrate conversion than CrNaY. This might be due to the retardation effect on TBHP decomposition (free radical formation) by the presence of small amounts of free 1c ligand in $\left[\mathrm{CrL}_{1 \mathrm{c}}\right] \mathrm{NaY}[50]$.

Table 4

Conversion, product selectivity and turn-over numbers for the oxidation of cyclohexene.

\begin{tabular}{|c|c|c|c|c|c|c|}
\hline \multirow[t]{2}{*}{ Catalyst } & \multirow[t]{2}{*}{ Cyclohexene conversion (\%) } & \multirow[t]{2}{*}{ Analytical error (\%) } & \multicolumn{3}{|c|}{ Product selectivity (\%) } & \multirow[t]{2}{*}{ TON } \\
\hline & & & CyOLl & CyONE & CyOX & \\
\hline (blank reaction) & 16.9 & \pm 5.9 & & & 100.0 & \\
\hline $\mathrm{NaY}$ & 11.1 & \pm 2.2 & & & 100.0 & \\
\hline HY & 28.7 & \pm 4.8 & & & 100.0 & \\
\hline $\mathrm{CrNaY}$ & 69.0 & \pm 1.8 & 21.6 & 67.8 & 10.7 & 190 \\
\hline$\left[\mathrm{CrL}_{1 \mathrm{a}}\right] \mathrm{NaY}$ & 56.0 & \pm 1.5 & 12.2 & 69.4 & 18.5 & 164 \\
\hline$\left[\mathrm{CrL}_{1 \mathrm{~b}}\right] \mathrm{NaY}$ & 55.1 & \pm 2.5 & 15.1 & 74.0 & 10.8 & 140 \\
\hline$\left[\mathrm{CrL}_{1 \mathrm{c}}\right] \mathrm{NaY}$ & 60.4 & \pm 3.1 & 15.4 & 71.6 & 13.0 & 173 \\
\hline $\mathrm{CrNaY}_{\mathrm{SBR}}$ & 61.2 & \pm 1.0 & 16.7 & 68.9 & 14.3 & 278 \\
\hline$\left[\mathrm{CrL}_{1 \mathrm{a}}\right] \mathrm{NaY}_{\mathrm{SBR}}$ & 60.8 & \pm 1.1 & 14.4 & 63.0 & 22.7 & 267 \\
\hline $\mathrm{CrHY}_{\mathrm{SBR}}$ & 72.9 & \pm 1.4 & 25.0 & 65.0 & 10.0 & 255 \\
\hline$\left[\mathrm{CrL}_{1 \mathrm{a}}\right] \mathrm{HY} Y_{\mathrm{SBR}}$ & 71.6 & \pm 1.3 & 22.8 & 66.8 & 10.3 & 269 \\
\hline
\end{tabular}


The lower substrate conversion for chromium complex modified catalysts is observed as it was for cyclohexanol oxidation. As it was mentioned above, the chromium entrapped in the zeolite by the biosorption process is in the trivalent form before calcination. The experimental evidences clearly demonstrated that part of the trivalent chromium impregnated onto zeolite surface is oxidised to hexavalent chromium during the calcination process, as it was seen for chromium(III) acetate impregnated onto silica gel [51]. During the calcination process, the bulky $\mathrm{CrO}_{3}$ can be gradually grafted onto zeolite surface through esterification reaction with surface hydroxyl groups [51,52]. It is still very difficult to distinguish between anchored $\mathrm{Cr}(\mathrm{VI})$ species from bulky $\mathrm{CrO}_{3}$ by XPS. Nevertheless, according to the results from Raman, TGA and XPS the existence of mixed oxidation states of chromium species, namely $\mathrm{Cr}(\mathrm{III})$ and $\mathrm{Cr}(\mathrm{VI})$ in the studied catalysts may be postulated. It is known from literature that $\mathrm{Cr}$ (III) complexes are active in oxidation of cyclohexene [53], as well as free $\mathrm{CrO}_{3}$ and anchored $\mathrm{Cr}(\mathrm{VI})$ species [54]. Thus, the triazenido complexes formed in zeolite matrix are also catalytically active but probably restrain the access of the substrate and oxidant to other catalytic active sites. The lowering of substrate conversion (cyclohexanol and cyclohexene) can be explained by the blocking effect of the complex formed.

\section{Conclusions}

Chromium complexes have been successfully prepared within biosorption FAU supports, using 1,3-diphenyltriazene derivatives. The electrowithdrawing properties of substituents of these ligands play an essential role in the coordination process. The supports, based in a low-cost system combining the biosorption properties of a microorganism with the ion exchange properties of a zeolite, were able to remove hexavalent chromium from contaminated water and were used for this immobilization. After the biosorption processes, FAU zeolites loaded with chromium were used as competitive catalysts in the oxidation of cyclohexanol and cyclohexene. CrNaY-derived catalysts promoted higher cyclohexanol conversion, whereas CrHY-derived catalysts presented bifunctionality for the oxidation of cyclohexene, ultimately yielding a higher conversion. The immobilization of chromium complexes proved to be efficient on limiting the metal leaching proneness observed on the untreated biosorption supports.

\section{Acknowledgments}

H. Figueiredo and B. Silva are thankful to the "FCT - Fundação para a Ciência e Tecnologia" for their respective research grants. IKB thanks FCT for the contract under the program Ciência 2007. This work was partially funded by the Centre of Biological Engineering and the Centre of Chemistry (University of Minho, Portugal) through FCT strategic projects PEst-OE/EQB/LA0023/ 2013 and PEst-C/QUI/UI0686/2011 (nF-COMP-01-0124-FEDER022716), the Project "BioEnv - Biotechnology and Bioengineering for a sustainable world", REF. NORTE-07-0124-FEDER-000048, co-funded by the Programa Operacional Regional do Norte (ON.2 - O Novo Norte), QREN and FEDER, and by the Spanish Ministry of Science and Innovation (CTQ2008-04261/PPQ).

\section{References}

[1] M. Gavrilescu, Removal of Heavy Metals from the Environment by Biosorption, Eng. Life Sci. 4 (2004) 219-232.

[2] E. Erdem, N. Karapinar, R. Donat, The removal of heavy metal cations by natural zeolites, J. Colloid Interface Sci. 280 (2004) 309-314.

[3] H. Eccles, Treatment of metal-contaminated wastes: why select a biological process?, Trends Biotechnol 17 (1999) 462-465.

[4] A. Agrawal, V. Kumar, B.D. Pandey, Remediation options for the treatment of electroplating and leather tanning effluent containing chromium - a review, Miner. Process. Extr. Metall. Rev. 27 (2006) 99-130.
[5] H. Figueiredo, I.C. Neves, C. Quintelas, T. Tavares, M. Taralunga, J. Mijoin, P. Magnoux, Oxidation catalysts prepared from biosorbents supported on zeolites, Appl. Catal. B Environ. 66 (2006) 274-280.

[6] H. Figueiredo, B. Silva, C. Quintelas, I.C. Neves, T. Tavares, Effect of the supporting zeolite structure on $\mathrm{Cr}$ biosorption: performance of a single step reactor and of a sequential batch reactor - a comparison study, Chem. Eng. J. 163 (2010) 22-27.

[7] H. Figueiredo, B. Silva, C. Quintelas, M.F.R. Pereira, I.C. Neves, T. Tavares, Biosorption of hexavalent chromium based on modified $\mathrm{Y}$ zeolites obtained by alkaline treatment, Environ. Eng. Manage. J. 9 (2010) 305-311.

[8] B. Silva, H. Figueiredo, I.C. Neves, T. Tavares, The role of $\mathrm{pH}$ on $\mathrm{Cr}$ (VI) reduction and removal by Arthrobacter Viscosus, Int. J. Chem. Biomol. Eng. 43 (2009) 5962.

[9] B. Silva, H. Figueiredo, C. Quintelas, I. Neves, T. Tavares, Zeolites as supports for the biorecovery of hexavalent and trivalent chromium, Microporous Mesoporous Mater. 116 (2008) 555-560.

[10] M.T. Tavares, C. Quintelas, H. Figueiredo, I. Neves, Comparative study between natural and artificial zeolites as supports for biosorption systems Maria Teresa tavares, Mater. Sci. Forum. 516 (2006) 1294-1298.

[11] B. Silva, H. Figueiredo, O.S.G.P. Soares, M.F.R. Pereira, J.L. Figueiredo, A.E. Lewandowska, M.A. Bañares, I.C. Neves, T. Tavares, Evaluation of ion exchangemodified $\mathrm{Y}$ and ZSM5 zeolites in $\mathrm{Cr}(\mathrm{VI})$ biosorption and catalytic oxidation of ethyl acetate, Appl. Catal. B Environ. 117-118 (2012) 406-413.

[12] I.W.C.E. Arends, R.A. Sheldon, Activities and stabilities of heterogeneous catalysts in selective liquid phase oxidations: recent developments, Appl. Catal. A Gen. 212 (2001) 175-187.

[13] Z. Lounis, A. Riahi, F. Djafri, J. Muzart, Chromium-exchanged zeolite (CrE-ZSM$5)$ as catalyst for alcohol oxidation and benzylic oxidation with t-BuOOH, Appl. Catal. A Gen. 309 (2006) 270-272.

[14] R.A. Sheldon, M. Wallau, I.W.C.E. Arends, U. Schuchardt, Heterogeneous catalysts for liquid-phase oxidations: philosophers' stones or Trojan Horses? Acc Chem. Res. 31 (1998) 485-493.

[15] D.E. De Vos, M. Dams, B.F. Sels, P.A. Jacobs, Ordered mesoporous and microporous molecular sieves functionalized with transition metal complexes as catalysts for selective organic transformations, Chem. Rev. 102 (2002) 3615-3640.

[16] D.E. Vos, P.P. Knops-Gerrits, R.F. Parton, B.M. Weckhuysen, P.A. Jacobs, R.A Schoonheydt, Coordination chemistry in zeolites, J. Incl. Phenom. Macrocycl. Chem. 21 (1995) 185-213.

[17] A. Corma, H. Garcia, Supramolecular host-guest systems in zeolites prepared by ship-in-a-bottle synthesis, Eur. J. Inorg. Chem. 2004 (2004) 1143-1164.

[18] P. McMorn, G.J. Hutchings, Heterogeneous enantioselective catalysts: strategies for the immobilisation of homogeneous catalysts, Chem. Soc. Rev. 33 (2004) 108-122.

[19] C.R. Jacob, S.P. Varkey, P. Ratnasamy, Selective oxidation over copper and manganese salens encapsulated in zeolites, Microporous Mesoporous Mater 22 (1998) 465-474.

[20] M. Salavati-Niasari, E. Zamani, M.R. Ganjali, P. Norouzi, Synthesis, characterization and liquid phase oxidation of cyclohexanol using tertbutylhydroperoxide over host (zeolite-Y)/guest (copper(II) complexes of 12 and 13-membered diaza dioxa Schiff-base macrocyclic ligand) nanocomposite materials (HGNM), J. Mol. Catal. A Chem. 261 (2007) 196-201.

[21] M. Jhansi, L. Kishore, K. Anand, A. Kumar, Kinetic study of oxidation of cyclohexanol using bimetallic iron-copper macrocyclic complex catalyst, Catal. Commun. 10 (2008) 285-290.

[22] J.-D. Lou, L.-H. Zhu, L.-L. Pan, L. Li, F. Li, C.-L. Gao, Solvent-Free Oxidation of Secondary Alcohols with Chromium Trioxide, Synth. React. Inorg. Met. NanoMetal Chem. 36 (2006) 585-587.

[23] C. Jin, W. Fan, Y. Jia, B. Fan, J. Ma, R. Li, Encapsulation of transition meta tetrahydro-Schiff base complexes in zeolite $\mathrm{Y}$ and their catalytic properties for the oxidation of cycloalkanes, J. Mol. Catal. A Chem. 249 (2006) 23-30.

[24] J. Muzart, Homogeneous CrVI-catalyzed benzylic, allylic and propargylic oxidations by tert-butyl hydroperoxide, Mini. Rev. Org. Chem. 6 (2009) 9-20.

[25] J. Muzart, Chromium-catalyzed oxidations in organic synthesis, Chem. Rev. 92 (1992) 113-140.

[26] B.M. Weckhuysen, I.E. Wachs, R.A. Schoonheydt, Surface chemistry and spectroscopy of chromium in inorganic oxides, Chem. Rev. 96 (1996) $3327-$ 3350.

[27] M. Menon, A. Pramanik, S. Chattopadhyay, N. Bag, A. Chakravorty, Chemistry of $[\mathrm{Ru}(1,3$-diaryltriazenide)2(PPh3)2]z $(\mathrm{z}=0,+)$. a hindered RuII, IIIN2P2 family with valence-independent geometry, Inorg. Chem. 34 (1995) 1361-1367.

[28] A.F.M.J. Van der Ploeg, G. Van Koten, K. Vrieze, Synthesis of novel dinuclear formamidino and triazenido compounds [2,6-(Me2NCH2)2C6H3](ptolNYNR)PtAgBr $(\mathrm{Y}=\mathrm{CH}, \mathrm{N})$ containing a platinum-silver bond, Inorg. Chem. 21 (1982) 2026-2031.

[29] H. Figueiredo, B. Silva, C. Quintelas, M.M.M. Raposo, P. Parpot, A.M. Fonseca, A.E. Lewandowska, M.A. Bañares, I.C. Neves, T. Tavares, Immobilization of chromium complexes in zeolite $\mathrm{Y}$ obtained from biosorbents: Synthesis, characterization and catalytic behaviour, Appl. Catal. B Environ. 94 (2010)1-7.

[30] D. Pfeiffer, I.A. Guzei, L.M. Liable-Sands, M.J. Heeg, A.L. Rheingold, C.H. Winter Synthesis, structure, and characterization of lanthanide complexes bearing 1,3-diphenyltriazenido ligands, J. Organomet. Chem. 588 (1999) 167-175.

[31] J.J. Nuricumbo-Escobar, C. Campos-Alvarado, G. Ríos-Moreno, D. MoralesMorales, P.J. Walsh, M. Parra-Hake, Binuclear palladium(I) and palladium(II) complexes of ortho-functionalized 1,3-bis(aryl)triazenido ligands, Inorg. Chem. 46 (2007) 6182-6189. 
[32] H. Figueiredo, B. Silva, M.M.M. Raposo, A.M. Fonseca, I.C. Neves, C. Quintelas, T. Tavares, Immobilization of $\mathrm{Fe}(\mathrm{III})$ complexes of pyridazine derivatives prepared from biosorbents supported on zeolites, Microporous Mesoporous Mater. 109 (2008) 163-171.

[33] P. Echlin, Low-voltage energy-dispersive X-ray microanalysis of bulk biological materials, Microsc. Microanal. 4 (1999) 577-584.

[34] S.-Y. Li, J. Millstone, C. Mirkin, V. Dravid, Detection of phosphorus in biological samples with analytical electron microscopy, Microsc. Microanal. 13 (2007) 456-457.

[35] L. Dambies, C. Guimon, S. Yiacoumi, E. Guibal, Characterization of metal ion interactions with chitosan by X-ray photoelectron spectroscopy, Colloids Surfaces A Physicochem. Eng. Asp. 177 (2000) 203-214.

[36] D. Park, Y.-S. Yun, J.M. Park, XAS and XPS studies on chromium-binding groups of biomaterial during $\mathrm{Cr}(\mathrm{VI})$ biosorption, J. Colloid Interface Sci. 317 (2008) 54-61.

[37] B.M. Weckhuysen, H.J. Spooren, R.A. Schoonheydt, A quantitative diffuse reflectance spectroscopy study of chromium-containing zeolites, Zeolites. 14 (1994) 450-457.

[38] Y. Huang, R.M. Paroli, A.H. Delgado, T.A. Richardson, An FT-Raman study of solid-state ion exchange in zeolites, Spectrochim Acta Part A Mol. Biomol. Spectrosc. 54 (1998) 1347-1354.

[39] B. Kwiecinska, I. Suárez-Ruiz, C. Paluszkiewicz, S. Rodriques, Raman spectroscopy of selected carbonaceous samples, Int. J. Coal Geol. 84 (2010) 206-212.

[40] P.-P. Knops-Gerrits, D. De Vos, E.J.P. Feijen, P.A. Jacobs, Raman spectroscopy on zeolites, Microporous Mater. 8 (1997) 3-17.

[41] S. Morin, P. Ayrault, N.S. Gnep, M. Guisnet, Influence of the framework composition of commercial HFAU zeolites on their activity and selectivity in m-xylene transformation, Appl. Catal. A Gen. 166 (1998) 281-292.

[42] K. Tanaka, C.-K. Choo, Y. Komatsu, K. Hamaguchi, M. Yamaki, T. Itoh, T. Nishigaya, R. Nakata, K. Morimoto, Characterization and preparation of chained Si species in zeolite supercages, J. Phys. Chem. B. 108 (2004) 25012508.

[43] C. Sedlmair, B. Gil, K. Seshan, A. Jentys, J.A. Lercher, An in situ IR study of the NOx adsorption/reduction mechanism on modified Y zeolites, Phys. Chem. Chem. Phys. 5 (2003) 1897-1905.
[44] B. Dutta, S. Jana, R. Bera, P.K. Saha, S. Koner, Immobilization of copper Schiff base complexes in zeolite matrix: preparation, characterization and catalytic study, Appl. Catal. A Gen. 318 (2007) 89-94.

[45] M. Álvaro, B. Ferrer, H. García, A. Sanjuán, Heterogeneous Gif oxidation of cyclohexane using Fe3+-picolinate complex encapsulated within zeolites, Tetrahedron. 55 (1999) 11895-11902.

[46] M. Salavati-Niasari, Host (nanopores of zeolite-Y)/guest [manganese(II) with 12-membered tetradentate $\mathrm{N}_{2} \mathrm{O}_{2}, \mathrm{~N}_{2} \mathrm{~S}_{2}$ and $\mathrm{N}_{4}$ donor macrocyclic ligands] nanocatalysts: flexible ligand synthesis, characterization and catalytic activity, Transition Met. Chem. 33 (2008) 443-452.

[47] H.S. Abbo, S.J.J. Titinchi, Synthesis and catalytic activity of $\mathrm{Cu}(\mathrm{II}), \mathrm{Fe}(\mathrm{III})$ and Bi(III) complexes of Thio-Schiff base encapsulated in zeolite-Y for hydroxylation of phenol, Top. Catal. 53 (2010) 254-264.

[48] I. Kuźniarska-Biernacka, K. Biernacki, A.L. Magalhães, A.M. Fonseca, I.C. Neves, Catalytic behavior of 1-(2-pyridylazo)-2-naphthol transition metal complexes encapsulated in Y zeolite, J. Catal. 278 (2011) 102-110.

[49] C.T. Dalton, K.M. Ryan, I.J. Langan, É.J. Coyne, D.G. Gilheany, Asymmetric alkene epoxidation with chromium oxo salen complexes: effect of $\pi$-rich and other types of additives, J. Mol. Catal. A Chem. 187 (2002) 179-187.

[50] G. Rothenberg, H. Wiener, Y. Sasson, Pyridines as bifunctional co-catalysts in the $\mathrm{CrO}_{3}$-catalyzed oxygenation of olefins by t-butyl hydroperoxide, J. Mol. Catal. A Chem. 136 (1998) 253-262.

[51] B. Liu, Y. Fang, M. Terano, High resolution X-ray photoelectron spectroscopic analysis of transformation of surface chromium species on Phillips $\mathrm{CrOx} / \mathrm{SiO}_{2}$ catalysts isothermally calcined at various temperatures, J. Mol. Catal. A Chem. 219 (2004) 165-173.

[52] A. Gaspar, J.L. Brito, L. Dieguez, Characterization of chromium species in catalysts for dehydrogenation and polymerization, J. Mol. Catal. A Chem. 203 (2003) 251-266

[53] P.B. Samnani, P.K. Bhattacharya, P.A. Ganeshpure, V.J. Koshy, S. Satish, Mixed ligand complexes of chromium(III) and iron(III): synthesis and evaluation as catalysts for oxidation of olefins, J. Mol. Catal. A Chem. 110 (1996) 89-94.

[54] A. Sakthivel, S.E. Dapurkar, P. Selvam, Allylic oxidation of cyclohexene over chromium containing mesoporous molecular sieves, Appl. Catal. A Gen. 246 (2003) 283-293. 